PREPARED FOR THE U.S. DEPARTMENT OF ENERGY, UNDER CONTRACT DE-AC02-76CH03073

PPPL-3677

PPPL-3677

UC-70

\author{
Study of the Effect \\ of Compressional Alfvén Modes on Thermal Transport \\ in the National Spherical Torus Experiment
}

by

E.D. Fredrickson, N. Gorelenkov, C.Z. Cheng, R. Bell, D. Darrow, D. Gates, D. Johnson, S. Kaye, B. LeBlanc, D. McCune, J. Menard, L. Roquemore, and S. Kubota

February 2002
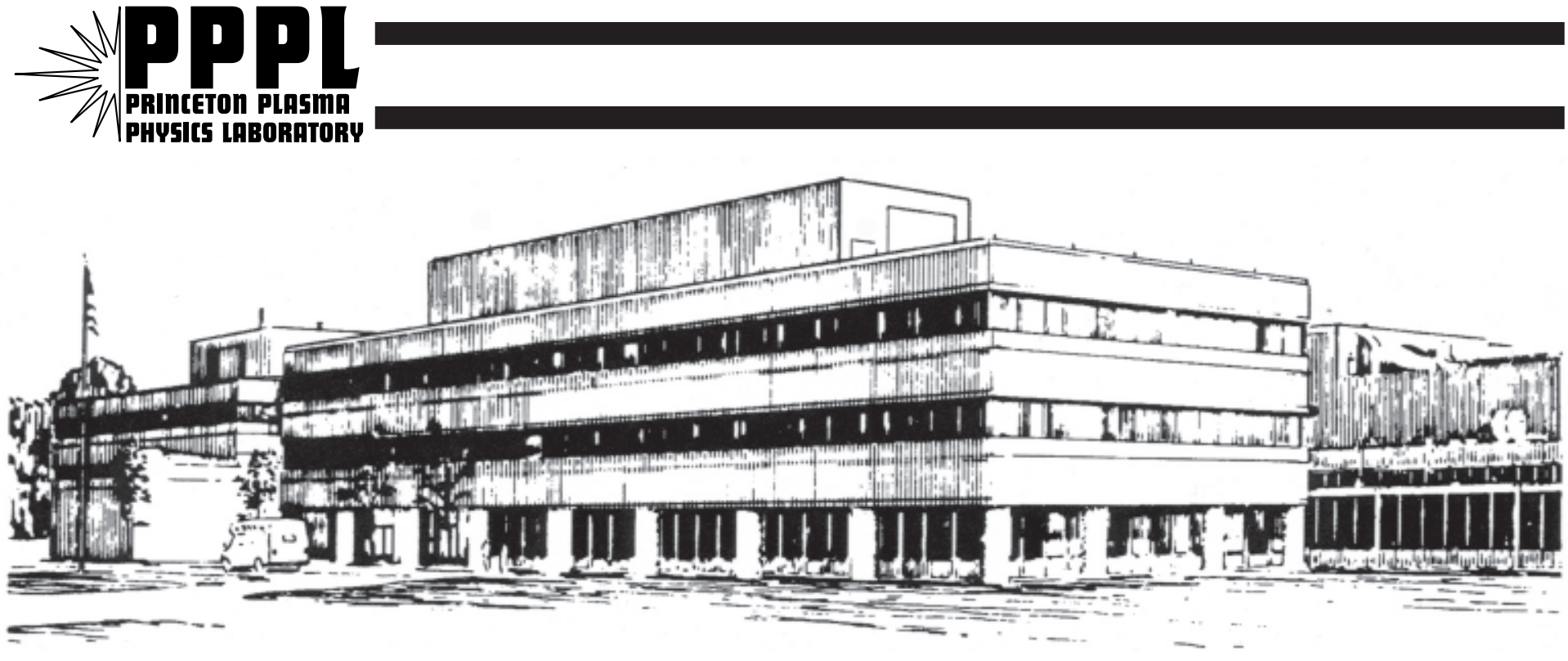

PRINCETON PLASMA PHYSICS LABORATORY PRINCETON UNIVERSITY, PRINCETON, NEW JERSEY 


\section{PPPL Reports Disclaimer}

This report was prepared as an account of work sponsored by an agency of the United States Government. Neither the United States Government nor any agency thereof, nor any of their employees, makes any warranty, express or implied, or assumes any legal liability or responsibility for the accuracy, completeness, or usefulness of any information, apparatus, product, or process disclosed, or represents that its use would not infringe privately owned rights. Reference herein to any specific commercial product, process, or service by trade name, trademark, manufacturer, or otherwise, does not necessarily constitute or imply its endorsement, recommendation, or favoring by the United States Government or any agency thereof. The views and opinions of authors expressed herein do not necessarily state or reflect those of the United States Government or any agency thereof.

\section{Availability}

This report is posted on the U.S. Department of Energy's Princeton Plasma Physics Laboratory Publications and Reports web site in Fiscal Year 2002. The home page for PPPL Reports and Publications is: http://www.pppl.gov/pub_report/

DOE and DOE Contractors can obtain copies of this report from:

U.S. Department of Energy

Office of Scientific and Technical Information

DOE Technical Information Services (DTIS)

P.O. Box 62

Oak Ridge, TN 37831

Telephone: (865) 576-8401

Fax: (865) 576-5728

Email: reports@adonis.osti.gov

This report is available to the general public from:

National Technical Information Service

U.S. Department of Commerce

5285 Port Royal Road

Springfield, VA 22161

Telephone: 1-800-553-6847 or

(703) 605-6000

Fax: (703) 321-8547

Internet: http://www.ntis.gov/ordering.htm 


\title{
Study of the effect of Compressional Alfvén Modes on thermal transport in the National Spherical Torus Experiment
}

\author{
E.D. Fredrickson, N. Gorelenkov, C.Z. Cheng, R. Bell, D. Darrow, D. Gates, D. \\ Johnson, S. Kaye, B. LeBlanc, D. McCune, J. Menard, L. Roquemore \\ Princeton Plasma Physics Laboratory, Princeton, New Jersey 08543
}

\begin{abstract}
S. Kubota
Institute of Plasma and Fusion Research, Univ. of California, Los Angeles California 90095 With the first injection of neutral beams into the National Spherical Torus Experiment

(NSTX) [Ono, et al., Nucl. Fusion 40 (2000) p557] a broad spectrum of fluctuations consisting of nearly equally spaced peaks in the frequency range from about 0.2 to 1.2 times the ion cyclotron frequency was observed. The frequencies scale with toroidal field and plasma density consistently with Alfvén waves. From these and other observations, the modes have been identified as Compressional Alfvén Eigenmodes (CAE). It has also recently been found that the ratio of the measured ion and electron temperatures in NSTX during neutral beam heating is anomalously high [Bell, Bull. Am. Phys. Soc. 46, p206 (2001)]. To explain the anomaly in the ratio of ion to electron temperature, it has been suggested that the CAE, driven by the beam ions, stochastically heat the thermal ions [Gates, et al., PRL 87, p205003 (2001)]. In this paper it is shown through studies of the power balance that stochastic heating of the thermal ions by the observed CAE alone is not solely responsible for the anomaly in the ion to electron temperature ratio.
\end{abstract}




\section{INTRODUCTION}

Compressional Alfvén modes excited by fast ions resulting from neutral beam injection (NBI) were seen for the first time [1] in the National Spherical Torus Experiment (NSTX) [2]. At the same time it was also found that the thermal ions were hotter than the electrons during NBI, more so than could be readily explained by the classical partition of beam power between the ions and the electrons and assuming classical electron-ion coupling, raising the possibility that the CAE were associated with this anomaly. In this paper we describe the CAE mode characteristics and investigate whether the CAE, driven by the beam ions, are damped on the thermal ions, and provide a channel for substantial energy flow between the beam ions and the thermal ions [3]. We will conclude, however, that it is unlikely that the observed CAE play a dominant role in the ion power balance and, indeed, that it is unlikely that any modification of the fast-ion to thermal ion energy transfer channel alone can resolve the anomaly of the high ion to electron temperature ratio for these discharges.

The practical realization of a fusion reactor based on magnetic confinement of a plasma will rely on the heating of the thermal plasma by super-Alfvénic $3.5 \mathrm{MeV}$ alpha particles from the D-T fusion reaction. In postulated reactor conditions, the alphas are expected to slow down classically and primarily heat the electrons. Coulomb collisions will then transfer energy from the electrons to the ions, supporting the fusion reaction. The energetic alphas may also excite, through wave-particle resonant interactions, a variety of instabilities such as Toroidal Alfvén Eigenmodes (TAE) [4], resonant TAE [5], Energetic Particle Modes (EPM) [6], and the fishbone instability [7] among others. In some cases, the interaction of the alphas with these instabilities can induce direct loss or redistribution [8-12], thereby imperiling the possibility of self-sustainment.

The TAE and EPM family of modes in the shear Alfvén branch have been extensively studied in experiments on TFTR [13-17], DIII-D [18-22], JT-60U [23-25], JET [26-29] and elsewhere, and have been found to be responsible for moderate to large losses of fast ions in these experiments [8-12]. In addition to the degradation of heating effectiveness, the localized losses associated with the TAE driven by ICRF tail ions were implicated in minor damage to the TFTR vacuum vessel [30]. The EPM were also, indirectly, 
implicated in affecting the performance of TFTR by inducing redistribution of the fast ion component which stabilized sawtooth relaxations, leading to giant sawtooth crashes [31].

The high frequency modes observed on NSTX appear to be compressional Alfvén Eigenmodes, rather than shear Alfvén modes like the TAE, RTAE, and EPMs described above. In cylindrical geometry it was shown that the spatial variation of the Alfvén velocity can provide the effect of a "potential well" for compressional Alfvén eigenmode growth [32]. This cylindrical model has since been extended to toroidal geometry [33], and in low aspect ratio toroidal geometry it was shown that the "potential well" becomes poloidally localized to the outboard midplane [34]. For the CAE the effective $\mathrm{k}_{\|}$remains small, the electron and ion Landau damping is weak, and the drive from fast ions can destabilize the mode. The ion cyclotron emission (ICE) seen on JET [35] and TFTR [36] is a possible experimental manifestation of CAE excited by fusion products [34], although other explanations have been proposed [37 and references therein].

In the case discussed here, the CAE are driven by the fast neutral beam ions and are expected to have weak damping on the thermal electrons via Landau damping. However, recent theoretical work on compressional Alfvén waves suggested that CAE can heat thermal ions through a non-resonant interaction if the wave amplitude is large enough $[3,38]$. In this model, if the wave amplitude is above a threshold of $\delta \mathrm{B} / \mathrm{B} \approx 3 \times 10^{-4}$, a spectrum of many CAE can stochastically heat thermal ions. This wave-mediated channeling of alpha energy to the thermal ion population, avoiding the electron channel, could clearly be beneficial for fusion power production $[39,40]$.

Stochastic ion heating by waves in the sub ion-cyclotron frequency range has previously been observed experimentally. In the Encore tokamak [41,42] a large amplitude drift-Alfvén wave with frequency of order half the ion cyclotron frequency in this case of $\mathrm{Ar}^{+}$ions was observed to cause strong heating through stochastic interactions of the thermal ions with the wave. This effect was numerically simulated and good agreement between experiment and theoretical predictions was found.

In Sect. II we describe the experiments conducted in the NSTX. In Sect. III we discuss interactions of the CAE with the fast ions and quantify required mode amplitudes and damping rates to achieve significant heating. In Sect. IV we will examine the kinetic 
profiles in an effort to determine the necessary levels of stochastic heating in NSTX to explain the anomalous ion temperature. We find that it is unlikely, for the discharges studied here, that these modes alone can entirely account for the measured anomalous difference between the electron and ion temperatures.

\section{EXPERIMENTAL PARAMETERS}

The National Spherical Torus Experiment (NSTX) is a low aspect ratio $(\mathrm{R} / \mathrm{a} \approx 0.85 \mathrm{~m}$ / $0.65 \mathrm{~m}$ ) toroidal device. The mission of the experiment is to establish the physics principles governing confinement and beta-limiting MHD instabilities and to assess the potential for future reactors. The experiments described here were performed in the first year of operation with neutral beam injection (NBI) heating.

The range of operational parameters used for the experiments discussed here are 0.7 to 1.0 MA toroidal plasma current, 0.3 to $0.45 \mathrm{~T}$ toroidal field at the nominal major radius, central electron density $1-5 \times 10^{19} \mathrm{~m}^{-3}$, central electron temperature up to about $1 \mathrm{keV}$. The plasmas were heated with $1.5-3 \mathrm{MW}$ of deuterium neutral beam injection (NBI) power at a full energy of $60-90 \mathrm{keV}$. The neutral beam consists of three sources whose tangency radii are $\approx 0.7,0.6$ and $0.5 \mathrm{~m}$. The beam velocity is $\mathrm{V}_{\mathrm{b}}(80 \mathrm{kV}) \approx 2.8 \mathrm{x}$ $10^{6} \mathrm{~m} / \mathrm{s}$ whereas the Alfvén velocity is $\mathrm{V}_{\mathrm{A}} \approx 0.9 \times 10^{6} \mathrm{~m} / \mathrm{s}$ at a typical electron density of $3 \times 10^{19} / \mathrm{m}^{3}$ and magnetic field of $0.3 \mathrm{~T}$ (for a nominal deuterium plasma). Thus, Alfvénic waves are likely to be excited.

Motivated by the prediction that beam-driven instabilities might be present at frequencies up to the ion cyclotron frequency, an array of high bandwidth magnetic pickup (Mirnov) coils was installed on NSTX prior to the commencement of NBI heating experiments. The coils have an internal resonance at $\approx 4.4 \mathrm{MHz}$. With the added capacitance of the leads the bandwidth is reduced to $2.5-3 \mathrm{MHz}$. There are three coils in the array mounted on the inner vacuum vessel walls, approximately $20 \mathrm{~cm}$ outside the plasma near the midplane and toroidally separated by $20^{\circ}$ and then $10^{\circ}$.

With the first injection of neutral beams on NSTX, a broad and complicated spectrum of coherent modes was seen between $\approx 400 \mathrm{kHz}$ and $2.5 \mathrm{MHz}\left(\mathrm{f}_{\mathrm{ci}}\right.$ for deuterium is $\approx 2.2 \mathrm{MHz}$ on the outboard midplane). The modes have been identified as compressional 
Alfvén eigenmodes (CAE) excited by a Doppler-shifted cyclotron resonance with the neutral beam ions [1]. There has been no indication of enhanced fast ion losses associated with the modes from either absolute neutron emission levels or direct measurements of lost beam ions. However, the fast ion loss probes [43] could miss localized losses making interpretation of these measurements difficult. The interpretation of the neutron emission rate measurements will be discussed in Sect. IV.

The principal diagnostics for detecting the modes are the array of fast Mirnov coils and a reflectometer system [44]. The core reflectometer can be stepped through four frequencies in the range $30-50 \mathrm{GHz}$, corresponding roughly to cut-off densities of 1.90 , 2.36, 2.73, and $3.14 \times 10^{19} \mathrm{~m}^{-3}$ during a beam pulse. The core reflectometer, at present, can only detect the presence of the mode and does not provide a measure of the absolute amplitude. Thus there is only a limited amount of experimental data available for studying the poloidal, toroidal and radial structure of the modes.

\section{CAE CHARACTERISTICS}

In this section, we present the characteristic features of the CAE and address the issue of the mode damping (and drive) rate. A model has been proposed that the CAE are driven by fast ions, and in turn stochastically heat the thermal ions $[3,38]$. We will look for evidence of this mechanism in the data from NSTX. The data will be derived from an experiment whose goal was to determine whether there might be any stochastic heating of the thermal ions by the CAE.

The theoretically predicted threshold (in slab geometry) for stochastic ion heating by an ensemble of modes is $\delta \mathrm{B}_{\mathrm{rms}} / \mathrm{B} \approx 3 \times 10^{-4}$, which implies a local rms magnetic fluctuation level of $\approx 1 \mathrm{G}$ in NSTX. The present theoretical models do not predict a complementary "stochastic drive" for the $\mathrm{CAE}$, meaning that the power flow from the fast ions to the CAE is limited by the linear, resonant drive. At the stochastic heating

threshold, the energy density in the wave field is $\mathrm{W}_{\mathrm{CAE}} \approx 4 \times 10^{-3} \mathrm{~J} \mathrm{~m}^{-3}$. Significant heating of the ions implies strong stochastic damping of the CAE, which requires an equally strong drive of the CAE by the fast beam ions for the modes to be maintained. To reach power densities comparable to the beam heating power densities, typically 
$\mathrm{P}_{\text {heat }}>40 \mathrm{~kW} \mathrm{~m}^{-3}$, the drive and damping rate must be of order $\gamma \approx \mathrm{P}_{\text {heat }} / \mathrm{W}_{\mathrm{CAE}} \approx 10^{7} / \mathrm{s}$. At this level of damping, $\gamma / \omega$ is of order unity or larger and it would be expected that no clear resonances would be seen. If the stochastic threshold, and hence the rms mode amplitude, was higher and the rms mode amplitude at saturation was 50 - 100 Gauss, the requirement on the damping rate would drop to $10^{4}$ to $10^{3} / \mathrm{s}$. However, at that point, the electron Landau damping would compete with the stochastic ion heating, resulting in partitioning of the power between thermal electrons and thermal ions. Other, more strongly damped modes might indeed make up the broadband, incoherent fluctuations in this frequency range, or alternatively additional strongly damped modes could be at frequencies greater than $\approx 2.5 \mathrm{MHz}$, but in the rest of this section we will concern ourselves with whether the observed spectral peaks in the frequency range up to $2.5 \mathrm{MHz}$ could play a role in the power balance.

The principal experimental measurements leading to the identification of these fluctuations as being CAE have been presented in Ref. 1. It was shown that the mode frequency had an Alfvénic scaling $\left(\propto B / n^{1 / 2}\right)$, the mode spectrum showed the hierarchy of peak splitting consistent with theoretical models of the compressional Alfvén eigenmodes, and the modes were clearly driven by a fast ion population from neutral beam injection. It was also shown that the modes are a characteristic resonant frequency of the plasma, and are, at least linearly, weakly unstable.

A typical example of CAE activity from this experiment is shown in Fig. 1. This is a spectrogram of voltage fluctuations (proportional to the time derivative of the poloidal magnetic field) on a Mirnov coil. The deuterium ion cyclotron frequency, $f_{c i}$ is approximately $2.2 \mathrm{MHz}$ on the outboard midplane.

In this experiment, short $(40 \mathrm{~ms})$ beam pulses were utilized in order to study CAE activity. As shown in Fig 1, one neutral beam source was injected during the current ramp-up phase; this was done to improve plasma reproducibility. Two short NBI pulses were subsequently injected during the current flattop. The purpose of these beam pulses was to excite the CAE activity and provide for two measurements of the ion temperature profile by charge-exchange recombination spectroscopy (CHERS) (each profile is integrated over $20 \mathrm{~ms}$ and the CHERS analysis method applied here uses subtraction of 
the background light measured before and after each pulse). Different sources were injected at different times to study the dependence of CAE activity on beam injection angle and voltage.

As seen in Fig. 1, the frequency of the CAE activity produced with this technique decreases with time. The drop is visible especially during the beam pulses from 0.22 to $0.26 \mathrm{~s}$ and $0.28-0.32 \mathrm{~s}$. The drop coincides with the increase in plasma density during the pulse. The modes can have a bursting character, as is seen during the first and second beam pulses, or they can be quasi-continuous, as during the third pulse.

An example of the initial growth of a mode, from the same shot shown in Fig. 1, is shown in Fig. 2. The mode growth is exponential between the noise level and the saturated level and the measured growth rate is thus inferred to be the difference of the linear drive and damping terms. The linear damping rate (electron Landau damping) is estimated to be about $10^{4} / \mathrm{s}$, implying a drive of this order also. There is no evidence for a non-linear increase in the mode drive as would be expected if, for example, some "stochastic drive" threshold were exceeded.

Following the turn-off of the NBI source, the modes decay rather rapidly. The rms magnetic fluctuation level between 0.95 and $1 \mathrm{MHz}$ through a time period encompassing the mode decay is shown in Fig. 3. The mode damping rate, as inferred from the decay rate of the rms fluctuation, is $\gamma_{\text {drive }}-\gamma_{\text {damping }} \approx 1.5 \times 10^{3} / \mathrm{s}$. This should be considered a lower bound on the linear mode damping rate as there may still be fast ion drive present during this period.

Prior to beam turn-off in Fig. 3, the mode amplitude has a bursting character, which modulates the mode amplitude by about $50 \%$. The growth and damping rates for these mode bursts are faster than the decay after beam turn-off, perhaps of order $1.1 \times 10^{4} / \mathrm{s}$.

For many resonant systems, the half width in the resonant frequency response is approximately the damping coefficient [45-47]. A single peak at the time of $0.261 \mathrm{~s}$ from the shot of Fig. 3 is shown in Fig. 4. The Fourier transform is calculated over a time period spanning roughly $1.6 \mathrm{~ms}$. The full width, $\delta \mathrm{f}$ of the peak at $70 \%$ amplitude (half power) is less than about $2 \mathrm{kHz}$, implying a damping rate, $\gamma \approx \delta \omega / 2<6 \times 10^{3} / \mathrm{s}$. Since some of the apparent width may derive from a slow frequency drift over the $1.6 \mathrm{~ms}$ 
Fourier transform window, this estimate of the damping rate may be considered an upper bound. Some non-linear saturation mechanisms can narrow the peak [48] and many processes, e.g., the secular frequency drifts mentioned above, can broaden the peak. Thus, this estimate of the damping on these modes together with the measured mode decay rates, only suggest that these modes are weakly damped. However, there is no direct evidence for damping rates approaching $10^{7} / \mathrm{s}$.

The mode decay time after beam turn-off is much shorter than the beam slowing down time of $\approx 55 \mathrm{~ms}$, inferred from the neutron decay rate [49], of $\approx 13 \mathrm{~ms}$. This is consistent with the modes being driven by a relatively small fraction of the beam ions near the injection energy. The modes (and the classical fast ion slowing down) would rapidly deplete this small population of fast ions, after which they could not be replaced during the beam slowing down process.

An experiment where the beam acceleration voltage was varied from $90 \mathrm{kV}$ to $56 \mathrm{kV}$ confirmed that the presence or absence of the modes was very sensitive to beam energy. This is shown qualitatively in Fig. 5 where spectrograms of Mirnov coil data taken during neutral beam injection pulses with primary fast ion energies of 90, 80, 70 and $56 \mathrm{keV}$ are compared. The $90 \mathrm{kV}$ beam excited larger and more numerous CAE modes than at $80 \mathrm{kV}$. At $70 \mathrm{kV}$ there was only one mode briefly visible and at $56 \mathrm{kV}$ there were no visible modes.

There is a substantial decrease in beam power as the voltage dropped from $90 \mathrm{kV}$ to $56 \mathrm{kV}$. At $90 \mathrm{kV}$ the beam power is approximately $2 \mathrm{MW}$ whereas at $56 \mathrm{kV}$ the power has dropped to $\approx 0.7 \mathrm{MW}$. However, by combining two sources, one at $70 \mathrm{kV}$ and one at $56 \mathrm{kV}$ the total injected power was increased to $2 \mathrm{MW}$. Only a single weak mode was seen with this combination. Thus, the threshold is apparently related to ion energy and not to heating power or, equivalently, fast ion beta.

The qualitative data from Fig. 5 is shown more quantitatively in Fig. 6 where the rms magnetic fluctuation level vs. the beam injection voltage is shown for 19 NBI pulses. An energy threshold for excitation of the modes is apparent at about $70 \mathrm{kV}$. Modes are excited in some shots at lower beam voltage, but for most the modes are absent. This result suggests that only the population of beam ions above $\approx 70 \mathrm{kV}$, which accounts for 10 to $15 \%$ of the power for $80 \mathrm{kV}$ beams, drives the modes. This constrains the power 
available to the CAE to transfer to the ions. Of course, modes at frequencies above the bandwidth of the present diagnostics, or broadband, turbulent modes may still be present; we are only discussing the observed CAE.

The change in the fast ion velocity between weak drive at $70 \mathrm{kV}$ and strong drive at $80 \mathrm{kV}$ is only about $6 \%$. This sensitivity to the beam voltage is not understood. The change in the beam deposition profile is modest for that change in voltage.

The beam voltage scan also provides an opportunity to look for an effect of the presence of CAE activity on the measured DD neutron rate, which arises predominantly from beam-target reactions. If the observed CAE modes were taking a significant amount of energy from the fast ion population between 70 and $80 \mathrm{keV}$, it would be expected that when they were present, TRANSP would over-predict the neutron rate compared to beam pulses where they were absent. The neutron detector is absolutely calibrated with an estimated accuracy of $\pm 20 \%$. The TRANSP [50] predictions of the neutron rate for the shots in this experiment were systematically lower than that measured by on average $\approx 30 \%$ for all beam injection energies. In Fig. 7 the measured rate for 56 , 70 and $80 \mathrm{kV}$ beams is compared to the TRANSP modeling which was scaled by 1.25. With this scale factor, the simulated neutron evolution and peak levels during NBI are in good agreement with the measured rates, independent of the presence or absence of observed CAE activity, indicating that the observed CAE modes do not have a significant effect on the most energetic fast ion population. TRANSP predicts a somewhat faster drop in neutron rate after each beam turn-off than is seen in the experiment meaning the calculated slowing down time for the fast ions is shorter than in the experiment.

\section{ION HEATING}

Power balance calculations using the TRANSP code find that the difference between the ion and electron temperatures outside the core is too large to be accounted for by classical heating and energy exchange processes [51,52]. Assuming classical beam deposition and thermalization and ion-electron coupling, the ion heat diffusivity, $\chi_{\mathrm{i}}$ inferred by TRANSP, is sometimes locally negative. This implies a flow of power to the ions through a channel not included in the analysis or problems such as absolute diagnostic calibration or analysis errors. This section describes analyses performed with 
TRANSP that explore the sensitivity of these results to the experimental uncertainties and to variations in the coupling of beam ion energy to thermal ions and electrons. Limits on the influence of possible ion heating by the observed CAE modes are discussed as well, but this power flow channel is not explicitly incorporated in the TRANSP code.

The TRANSP code can be used both as a simulation and an analysis tool to explore different assumptions about the thermal transport and partitioning of heat sources. In the semi-predictive approach, TRANSP uses the electron density and temperature profiles measured at 60 times per sec at ten radial positions with a Thomson scattering system $[53,54]$, the radiated power profile, and the calculated beam and ohmic heating profiles to calculate $\chi_{\mathrm{e}}$, but simulates the evolution of the ion temperature profile. The simulation can be done with a variety of models for the ion transport, partitioning of beam heating power and electron-ion coupling. The simulated ion temperature profiles are then compared to the measured profiles. In the analysis approach, the ion conductive power flow is estimated through a full power balance calculation using the measured ion temperature profile and measured $\mathrm{Z}_{\mathrm{eff}}$ (necessary to get the ion density).

All of the shots studied, including those with the lowest injected beam power, had anomalously high ion temperature. We will concentrate our analysis on the pair of shots used for Fig. 5 in which the beam voltage was changed from 90 to $56 \mathrm{kV}$. In Fig. 8, the measured ion temperature profile for the $80 \mathrm{kV}$ beam case is compared with that simulated by TRANSP, assuming that the ion transport is neoclassical according to Chang-Hinton [55] (curve labeled "a"). The Chang-Hinton thermal diffusivity is close to the NCLASS [56] value. The measured ion temperature is significantly higher than the neoclassical simulated temperature out to a major radius of about $1.4 \mathrm{~m}$. This power balance analysis finds that the ion-electron coupling and the beam heating of the ions are the dominant terms in the ion power balance. The thermal transport (with neoclassical $\chi)$, the convective transport and the $\mathrm{dT}_{\mathrm{i}} / \mathrm{dt}$ terms were small.

The large ratio of the beam injection energy to electron temperature results in a classical partition of the beam heating to electrons and ions in a 2:1 proportion. As a test, we have arbitrarily re-apportioned the heating power in a 1:2 proportion (electrons:ions) without changing the power deposition profiles, and we have again predicted the ion 
temperature profile again using the neoclassical ion thermal transport assumption. The reapportionment added approximately $370 \mathrm{~kW}$ of heating power to the thermal ions. This results in approximate agreement between the predicted and measured $\mathrm{T}_{\mathrm{i}}(\mathrm{R})$ (curve " $\mathrm{b}$ "). This result, that an arbitrary re-apportionment of $\approx 1 / 3$ of the absorbed beam heating power from the electrons to the ions could explain the ion temperature anomaly, was fairly typical of the data set for this experiment. However, it was shown in the previous section that only $\approx 13 \%$ of the energy in the injected fast ions, that between 70 and $80 \mathrm{keV}$, drives the modes. The total injected beam power for this shot is $1.6 \mathrm{MW}$, thus there is about $200 \mathrm{~kW}$ to drive the detected CAE, and consequently heat the ions. This is only slightly more than half of what is required to match the measured temperature. Diverting all of this energy from the fast ion population above $70 \mathrm{keV}$ would be expected to have a substantial impact on the neutron rate. The calculated rate matches the experiment within $25 \%$, however.

In the low beam voltage, lowest power case without detected CAE activity, there was also an anomalously large difference between $\mathrm{T}_{\mathrm{i}}$ and $\mathrm{T}_{\mathrm{e}}$. The measured ion temperature (solid circles) compared to the neoclassical TRANSP simulation (curve labeled "a") is shown in Fig. 9. The ions are again a few hundred $\mathrm{eV}$ hotter than the electrons, and well above the neoclassical simulation of the ion temperature. In this case, though, diverting $50 \%$ of the beam power from the electrons to the ions results in a predicted ion temperature still much lower than the measured ion temperature (curve labeled " $b$ "). Diverting the total local beam power from the electrons to the ions was also insufficient to match the measured ion temperature profile.

Thus far, variation of the ion or electron temperatures required to resolve the power transfer puzzles requires deviation of the measurements that are outside their understood uncertainties. It was found that a reduction (increase) in the ion (electron) temperature across the profile of more than $30 \%$, well outside the known measurement uncertainties and effectively making the ion and electron temperatures equal, was required to bring the ions into classical power balance. For nine discharges analyzed in this experiment, the TRANSP analysis using the measured ion and electron temperature and electron density predicted a kinetic stored energy (the sum of the thermal ion and electron energy and the beam fast ion energy) approximately $10 \%$ lower than the EFIT calculations using the 
magnetics data (considered reasonable agreement). Decreasing the ion temperature by $30 \%$ results in a $10-15 \%$ decrease in the stored energy inferred by TRANSP, worsening the comparison of stored energy between TRANSP and EFIT.

The analysis of this low beam voltage shot is of particular interest in that the possibility of other, undetected modes, either above $2.5 \mathrm{MHz}$ or below the "background noise" level (or indeed responsible for it), which might also couple fast ion energy to the thermal ions is excluded. No channeling of fast ion energy to thermal ions would be adequate to achieve power balance. This is clearly an unresolved mystery.

While the neutral beam power of $710 \mathrm{~kW}$ was insufficient by itself to support the ion temperature for the low voltage shot, there is an additional $600 \mathrm{~kW}$ of Ohmic heating power. Observations of anomalous ion temperatures in ohmically heated plasmas have previously been reported from early tokamak experiments, spheromaks and field reversed configurations and particularly RFP's [c.f. refs. 41, 42, 57-61 and references therein]. In all of these experiments, power flow to the ions through channels other than the classical electron-ion collisional coupling was inferred. The mechanisms invoked to explain the anomalous ion heating in these other devices are being considered as possible explanations for the ion temperature anomaly in NSTX.

\section{SUMMARY}

In summary, multiple, coherent modes at frequencies up to the deuterium ion cyclotron frequency were observed during neutral beam injection heating of the National Spherical Torus Experiment (NSTX). The modes were seen predominantly in the frequency range of $0.4 \mathrm{kHz}$ to $2.5 \mathrm{MHz}$ (the upper limit of the detector response). The modes are Alfvénic in character in that the mode frequency scales nearly linearly with magnetic field and inversely with the square root of the density [1]. They have been identified as compressional Alfvén waves excited by the energetic beam ions. The parametric scaling of the mode frequency with density and magnetic field is consistent with CAE modes. To date there has been no observation of enhanced beam ion loss associated with the mode activity.

Recent theoretical work has suggested that modes in this frequency range can stochastically heat the thermal ions if the mode amplitude is larger than a threshold of 
$\delta \mathrm{B} / \mathrm{B} \approx 3 \times 10^{-4}$, possibly explaining the anomalously high ion temperatures observed on NSTX [40]. In this paper we have shown the observed CAE modes are apparently driven by only the most energetic beam ions (> $70 \mathrm{kV})$, limiting the beam ion energy available to be transferred to the thermal ions. We also find that the presence or absence of CAE activity has no discernable effect on the neutron emission. Of course, as has been suggested earlier, all CAE activity may not be detected with the present diagnostic set. The coherence of the individual instabilities (line widths of less than $2-3 \mathrm{kHz}$ ) suggests a very weakly damped plasma resonance $(\mathrm{Q}>300)$. This is also consistent with observed decay rates for the modes of $2 \times 10^{3}$ to $1 \times 10^{4} / \mathrm{s}$. Finally, in the lowest beam power case TRANSP analysis finds that the total absorbed beam power is not sufficient to support the measured ion temperature, assuming classical electron-ion coupling. We conclude that the observed CAE cannot be solely responsible for the large difference between the electron and ion temperatures.

Anomalously high ion temperatures are observed in NSTX plasmas with and without detectable CAE activity. Further, the inferred deficit in ion heating power for the nonCAE or lowest power case shown here is greater than the total absorbed neutral beam heating power. Thus, in the low beam voltage shot some explanation other than CAE stochastic heating of the thermal ions is necessary to explain the high measured ion temperatures. Further, in the higher beam voltage shots with detected CAE activity, the behavior of the modes at beam turn-off, the threshold for mode excitation at beam energies greater than $70 \mathrm{keV}$ and the narrow line widths and slow growth and damping all point to weakly driven, weakly damped instabilities which could not transfer substantial amounts of power from the fast ion population to the thermal ions.

The strength of these conclusions is weakened by the limited amount of data, as well as the limited experience with the diagnostic measurements on NSTX. Corrections of order $20-30 \%$ in this data set to either the electron or ion temperature measurement would ease most of the power balance anomalies. These corrections exceed our present understanding of the uncertainties in this measurement and in some instances would impact the otherwise good agreement of magnetic and kinetic stored energy estimates. While the estimated uncertainty in NBI power of order 15-20\% would help the global power balance for the last shot, it would not solve the problem. 
Future experiments are being planned to explore this issue more extensively. In order to address the possibility that as yet undetected modes may play a role in the ion heating, magnetics sensors and amplifiers that will extend the bandwidth to higher frequencies are being installed. Also, capability to make absolute measurements of the mode amplitudes with reflectometry is being developed. Together with improvements in theoretical tools, such measurements will enable a quantitative assessment of the range of heating rates possible by this mode activity.

The authors greatly appreciate the support of the NSTX group in these experiments, in particular many helpful suggestions from Dr. M. Bell. This work supported by U.S. DOE Contract DE-AC02-76CH03073 and Grant Nos. DE-FG03-99ER54527 and DEFG03-86ER53225. 


\section{Bibliography}

[1] E D Fredrickson, N. Gorelenkov, C Z Cheng, et al., Phys Rev. Lett. 87, (2001) 145001 .

[2] M. Ono, et al., Nucl. Fusion 40 (2000) 557.

[3] D. Gates, R. White, N. Gorelenkov, Phys. Rev. Lett 87 p205003 (2001).

[4] C.Z. Cheng and M.S. Chance, Phys. Fluids 29, (1986) 2471.

[5] C Z Cheng, N N Gorelenkov, and C T Hsu, Nucl. Fusion 35, 1639 (1995).

[6] F Zonca and L Chen, Phys. Plasmas 3, 323 (1996).

[7] K. M. McGuire, R. Goldston, M Bell, et al., Phys. Rev. Lett. 50891 (1983).

[8] D S Darrow, S J Zweben, Z Chang, C Z Cheng, M D Diesso, E D Fredrickson, E Mazzucato, R Nazikian, C K Phillips, S Popovichev, M H Redi, R B White, J R Wilson, K L Wong, Nucl. Fusion 37939 (1997).

[9] S J Zweben, R V Budny, D S Darrow, S S Medley, R Nazikian, B C Stratton, E J Synakowski, G Taylor, Nucl Fusion 40 p91 (2000).

[10] H H Duong, W W Heidbrink, E J Strait, T W Petrie, R Lee, R A Moyer, J G Watkins, Nucl. Fusion 33, 749 (1993).

[11] H.H. Duong, W.W Heidbrink, Nucl. Fusion 33211 (1993).

[12] H Kimura, M Saigusa, S Moriyama, T Kondoh, Y Neyatani, T Ozeki, T Nishitani, Y Kusama, T Fujii, M Sato, M Nemoto, K Tobita, C Z Cheng, Phys. Lett. A 19986 (1995).

[13] K.L. Wong, R.J. Fonk, S.F. Paul, et al., Phys. Rev. Lett. 66, (1991) 1874.

[14] J R Wilson, K L Wong, E D Fredrickson, Z Chang, R Nazikian, E Mazzucato, D Darrow, C K Phillips, G Y Fu, M P Petrov, A V Khudaleev, Proc. $14^{\text {th }}$ Int. Conf. On Plasma Physics and Controlled Nuclear Fusion Research (Vienna: IAEA) Vol. I, p661 (1992).

[15] E.D. Fredrickson, M G Bell, R Budny, Z Chang, C Z Cheng, G Y Fu, E Mazzucato, R Nazikian, A T Janos, K. M. McGuire, R Majeski, C K Phillips, G Schilling, G Taylor, and J R Wilson, Nuclear Fusion 35 (1995) 1457

[16] S Bernabei, R V Budny, E D Fredrickson, et al., Nucl. Fusion 41 (2001) 513.

[17] K L Wong, Plasma Phys. and Control. Fusion 41 pR1 (1999). 
[18] W W Heidbrink, E J Strait, E Doyle, G Sager, R T Snider, Nucl. Fusion 31 (1991) 1635 .

[19] E J Strait, W W Heidbrink A D Turnbull, M S Chu, H H Duong, Nucl. Fusion 33 1849 (1993)

[20] W W Heidbrink, H H Duong, J Manson, E Wilfrid, C Oberman, Phys. Fluids B 5 2176 (1993).

[21] W W Heidbrink, E J Strait, M S Chu, A D Turnbull, Phys. Rev. Lett. 71855 (1996).

[22] W. W. Heidbrink, E. D. Fredrickson, T. K. Mau, C. C. Petty, R.I. Pinsker, M.

Porkolab, B.W. Rice, Nucl. Fusion 39, 1369 (1999).

[23] M Saigusa, h Kimura, S Moriyama, Y Neyatani, T Fujii, Y Koide, T kondoh, M Sato, M Nemoto, Y Kamada, and JT-60 team, Plasma Phys. Control. Fusion 37295 (1995).

[24] H Kimura, M Saigusa, S Moriyama, T Kondoh, Y Neyatani, T Ozeki, T Nishitani, Y Kusama, T Fujii, M Sato, M Nemoto, K Tobita, C Z Cheng, Phys. Lett. A 199, 86 (1995).

[25] M Saigusa, H Kimura, Y Kusama, G J Kramer, T Ozeki, S Moriyama, T Oikawa, Y Neyetani, and T Kondoh, Plasma Phys. Control. Fusion 401647 (1998).

[26] S Ali-Arshad and D J Campbell, Plasma Phys. and Control. Fusion 37715 (1995).

[27] A Fasoli, D Borba, G Bosia, D J Campbell, J A Dobbing, C Gormezano, J Jacquinot, P Lavanchy, J B Lister, p Marmillod, J M Moret, A Santagiustina, and S Sharapov, Phys. Rev. Lett. 75645 (1995).

[28] A Fasoli, D Borba, C Gormezano, R Heeter, A Jaun, J Jacquinot, W Kerner, Q King, J B Lister, S Sharapov, D Start, and L Villard, Plasma Phys. and Control. Fusion 39 B 287 (1997)

[29] A Fasoli, J A Dobbing, C Gormezano, J Jacquinot, J B Lister, S E Sharapov, A Sibley, Nucl. Fusion 36258 (1996).

[30] R.B. White, E.Fredrickson, D. Darrow, M. Zarnstorff, R. Wilson, S. Zweben, K. Hill, Y. Chen, and G. Fu, Phys. Plasmas 2 (1995) 2871.

[31] S. Bernabei, M G Bell, R V Budny, E D Fredrickson, N N Gorelenkov, J C Hosea, R Majeski, E Mazzucato, C K Phillips, G Schilling, and J R Wilson, Phse Rev. Lett. 84, 1212 (2000). 
[32] S.M. Mahajan, D.W. Ross, Phys. Fluids 26 (1983) 2561.

[33] B. Coppi, S. Cowley, R. Kulsrud, P. Detragiache, and F. Pegoraro, Phys. Fluids 29, (1986) 4060.

[34] N.N. Gorelenkov, C.Z. Cheng, Nucl. Fusion 35, (1995) 1743.

[35] G A Cottrell, R O Dendy, Phys. Rev. Lett. 6033 (1988).

[36] S. Cauffman and R. Majeski, Rev. Sci. Instrum. 66, (1995) 817.

[37] V. Arunasalam, G.J. Greene, K.M. Young, Nucl. Fusion 34 p927 (1994)

[38] L. Chen, Z. Lin, R. White, Phys. of Plasmas 8 p4713 (2001).

[38] D. Gates, R. White, N. Gorelenkov, Phys. Rev. Lett 87 p205003 (2001).

[39] N.J. Fisch, J-R. Rax, Phys. Rev. Lett. 69 (1992) 612.

[40] M C Herrmann and N Fisch, Phys. Rev. Lett. 79 (1997) 1495.

[41] J M McChesney, R A Stern, P M Bellan, Phys. Rev. Lett. 59 (1987) 1436.

[42] J M McChesney, P M Bellan, R A Stern, Phys. Fluids B 3 (1991) 3363.

[43] D.S. Darrow, R. Bell, D.W. Johnson, H. Kugel, J.R. Wilson, F.E. Cecil, R. Maingi, A. Krasilnikov, A. Alekseyev, Rev. Sci. Instrum. 72, p784 (2001).

[44] S. Kubota, X.V. Nguyen, W.A. Peebles, et al., Rev. Sci. Instrum., 72, (2001) 348.

[45] J D Jackson, 1962 Classical Electrodynamics, (New York: Wiley) Ch. 8.

[46] K-L Wong, Phys. Fluids 212108 (1978).

[47] A Yariv, 1975 Quantum Electronics, $2^{\text {nd }}$ Edition, (New York: Wiley) p302.

[48] W W Heidbrink, Private Communication.

[49] W W Heidbrink, J Kim, R J Groebner, Nucl. Fusion 281897 (1988).

[50] R. V. Budny, Nucl. Fusion 34, 1247 (1994), and references therein.

[51] R. Bell, "Transport Properties of Auxiliary Heated NSTX Plasmas", Bulletin of the American Physical Society 46, p206 (2001).

[52] J. Menard, in Proceedings of the $28^{\text {th }}$ European Conference, Madiera, Portugal, 2001 [Plasma Phys. Controlled Fusion (to be published)].

[53] D.W. Johnson, N. Bretz, B. LeBlanc, R. Palladino, D. Long, R. Parsells, Rev. Sci. Instrum. 70, p776 (1999).

[54] D.W. Johnson, B.P. LeBlanc, D.L. Long, G. Renda, Rev. Sci. Instrum. 72, p1129 (2001).

[55] S.P. Hirschman and D.J. Sigmar, Nucl. Fusion 21, 1079 (1981). 
[56] W. Houlberg, K. Shang, S. Hirshman, and M. Zarnstorff, Phys. of Plasmas 4, 3230 (1997).

[57] M.G. Bell, I.H. Hutchinson and J.D. Strachan, in Proceedings of the $7^{\text {th }}$ European Conference on Controlled Fusion and Plasma Physics, Vol. I, p 16. \{Centre de Recherches en Physique des Plasmas (CRPP), Ecole Polytechnique Fédéral de Lausanne, Switzerland].

[58] R.B. Howell, Y. Nagayama, Phys. Fluids 28, (1985) 743.

[59] T. Fujita, K. Saito, J. Matsui, Y. Kamada, H. Morimoto, Z. Yoshida, N. Inoue, Nucl. Fusion 31 (1991) 3.

[60] E. Scime, M. Cekic, D.J. Den Hartog, S. Hokin, D.J. Holly, C. Watts, Phys. Fluids B 4, (1992) 4062.

[61] S. A. Hokin, Nucl. Fusion 37, (1997) 1615. 


\section{Figure Captions}

Fig. 1 Spectrogram of Mirnov coil fluctuations showing bursts of CAE activity for a typical discharge in this experiment. Source A, Rtan $\approx 70 \mathrm{~cm}$ from 0.06 to 0.18 s @ $79 \mathrm{kV}$, source B, Rtan $\approx 60 \mathrm{~cm}$ from 0.22 to $0.26 \mathrm{~s} @ 89 \mathrm{kV}$ and source $\mathrm{C}$, Rtan $50 \mathrm{~cm}$ from 0.28 to $0.32 \mathrm{~s} @ \approx 75 \mathrm{kV}$.

Fig. 2 Detail of Mirnov coil spectrogram showing mode damping at end of NBI injection. (Source C, Rtan 50 cm, @ 80 kV)

Fig. 3 Mode amplitude showing exponential decay after NBI turns off at 0.26s. Decay rate of bursts is also indicated. Same shot as in Fig. 2.

Fig. 4 Single spectra from Fig. 3 at 0.26s. Typical peak "widths at half maximum" are less than $3 \mathrm{kHz}$.

Fig. 5 Spectrograms of Mirnov coil data taken during four neutral beam pulses. The neutral beam injection energy varied from $\approx 90 \mathrm{kV}$ to $\approx 60 \mathrm{kV}$. The pulse duration is indicated by the black bar at the top of each spectrogram (a) Source B, Rtan $\approx$ $60 \mathrm{~cm}, 90 \mathrm{kV}, 2.1 \mathrm{MW}$, (b) Source C, Rtan 50 cm, 80 kV, $1.6 \mathrm{MW}$, (c) Source $\mathrm{A}, \operatorname{Rtan} \approx 70 \mathrm{~cm}, 70 \mathrm{kV}, 1.3 \mathrm{MW}$, (d) source C, Rtan $50 \mathrm{~cm}, 56 \mathrm{kV}, 0.7 \mathrm{MW}$.

Fig. 6 Peak RMS fluctuation level during a beam pulse vs. the beam injection voltage. A threshold for mode excitation is seen at about $70 \mathrm{kV}$. (Please note the logarithmic abscissa.)

Fig. 7 Relative comparison of the measured neutron rate evolution to that simulated with TRANSP. The TRANSP simulation has been scaled by $\approx 1.25$. The last beam pulse was at $\approx 56 \mathrm{kV}$.

Fig. 8 Comparison of measured ion temperature (solid circles) with TRANSP simulated ion temperature using, a) neoclassical thermal diffusivity, b) neoclassical thermal diffusivity with $50 \%$ of NBI power to electrons diverted to ions. The error bars on the ion temperature points represent one sigma statistical uncertainty. Also shown (open circles) are the outboard Thomson scattering electron temperature points and their statistical error bars (smaller than the symbols). 
Fig. 9 Comparison of measured ion temperature (solid circles) with TRANSP simulated ion temperature using, a) neoclassical thermal diffusivity, b) neoclassical thermal diffusivity with $50 \%$ of NBI power to electrons diverted to ions. Also shown (open circles) are the outboard Thomson scattering electron temperature points. 
Figure 1

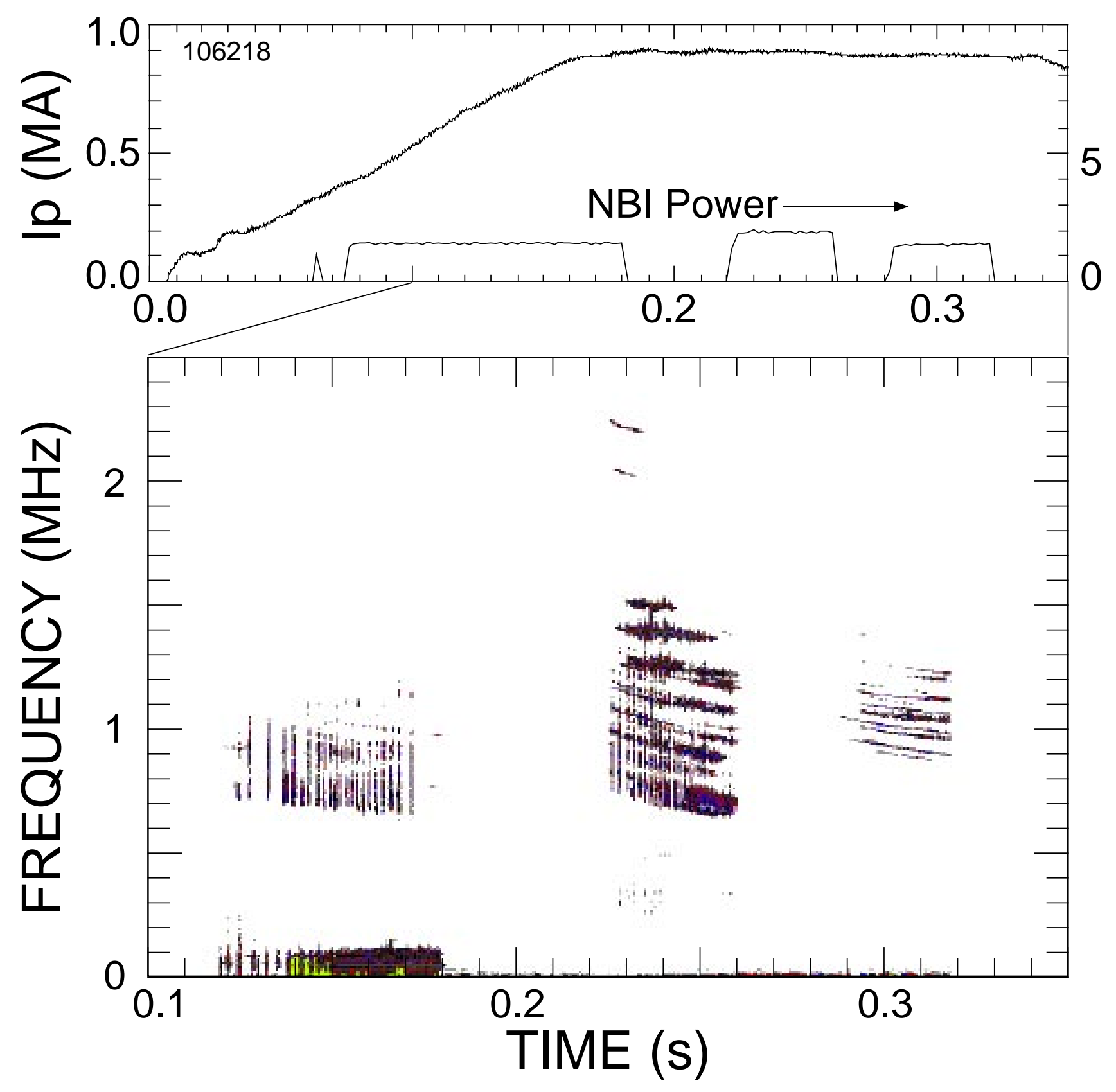


Figure 2

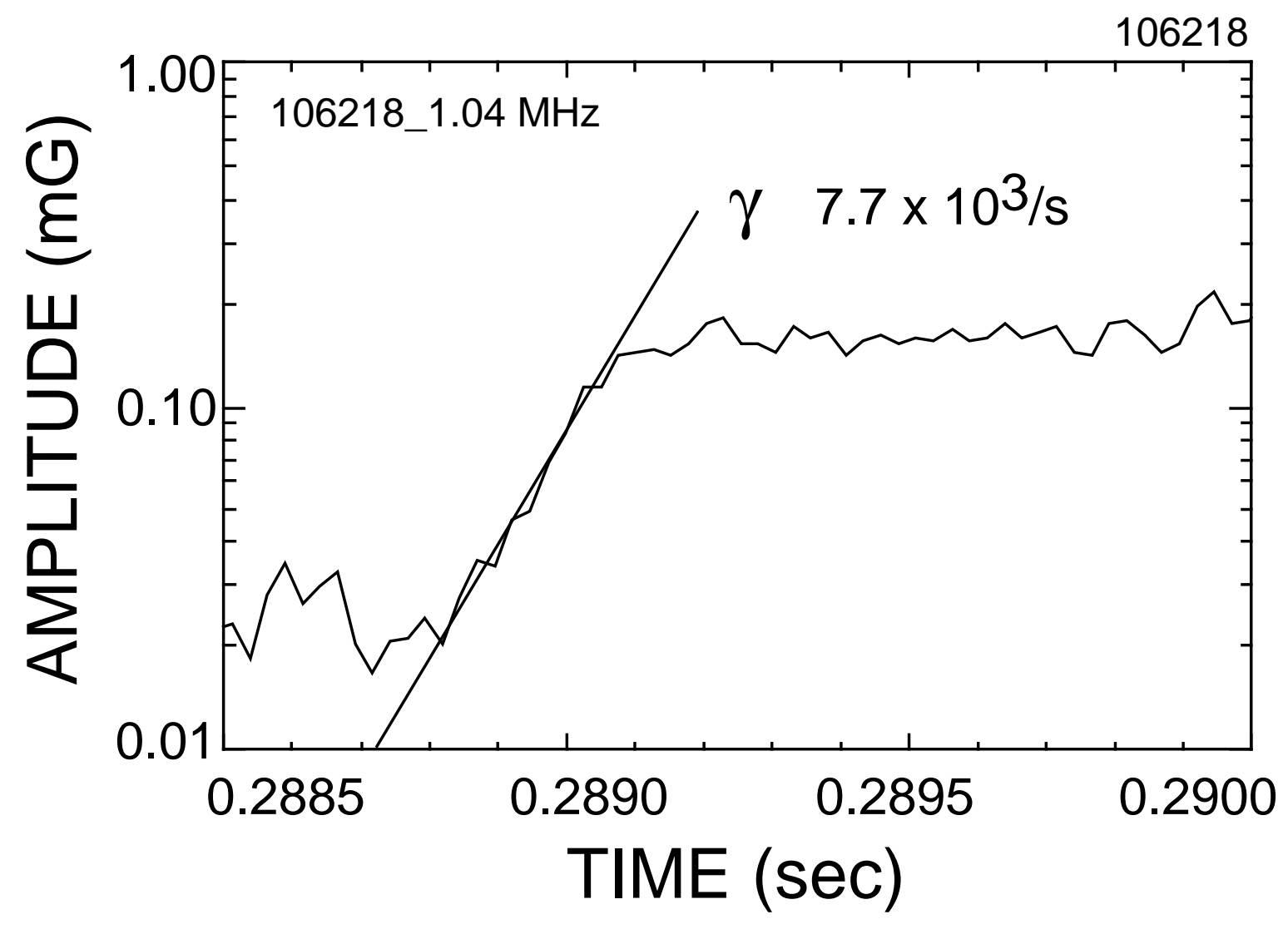


Figure 3

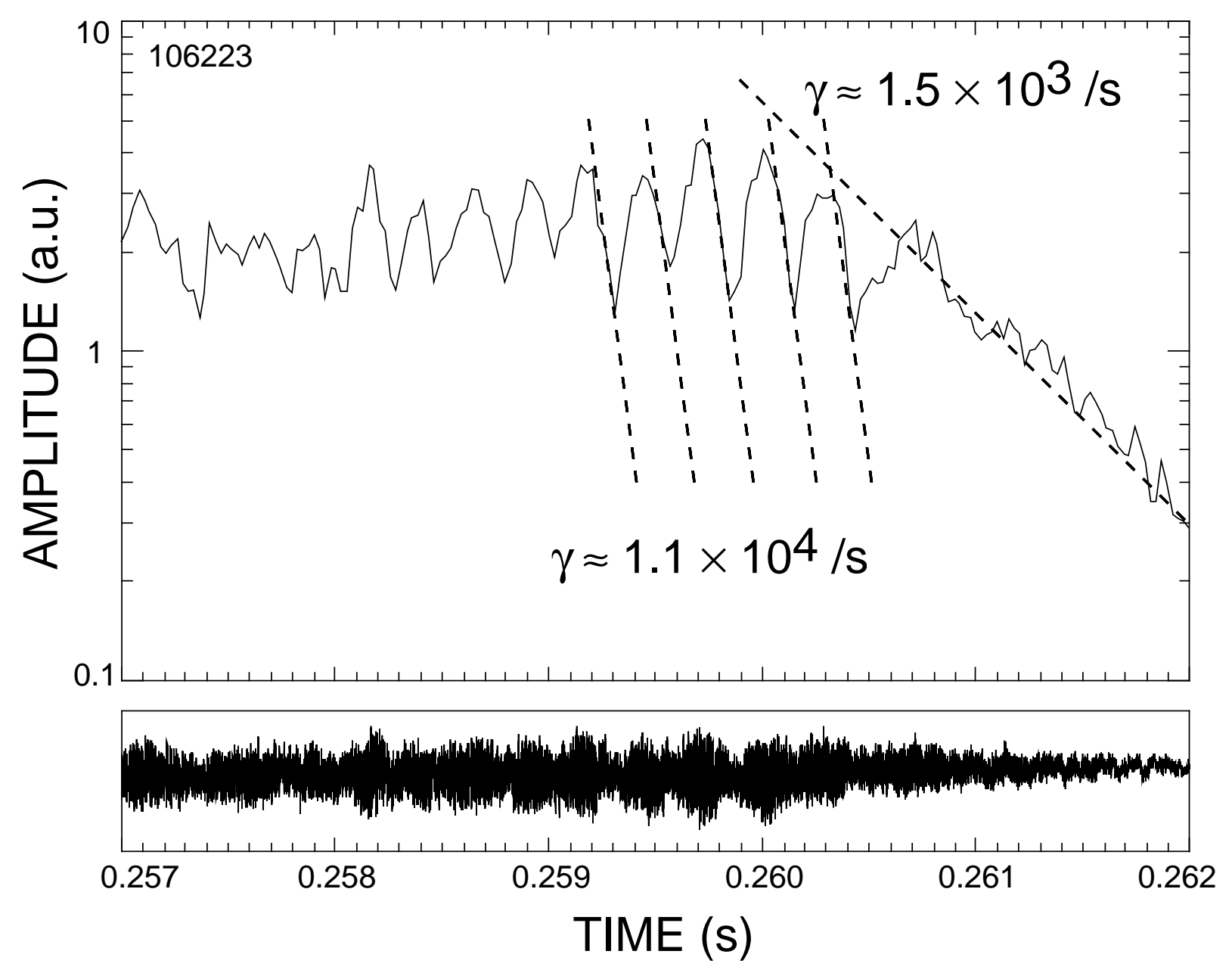


Figure 4

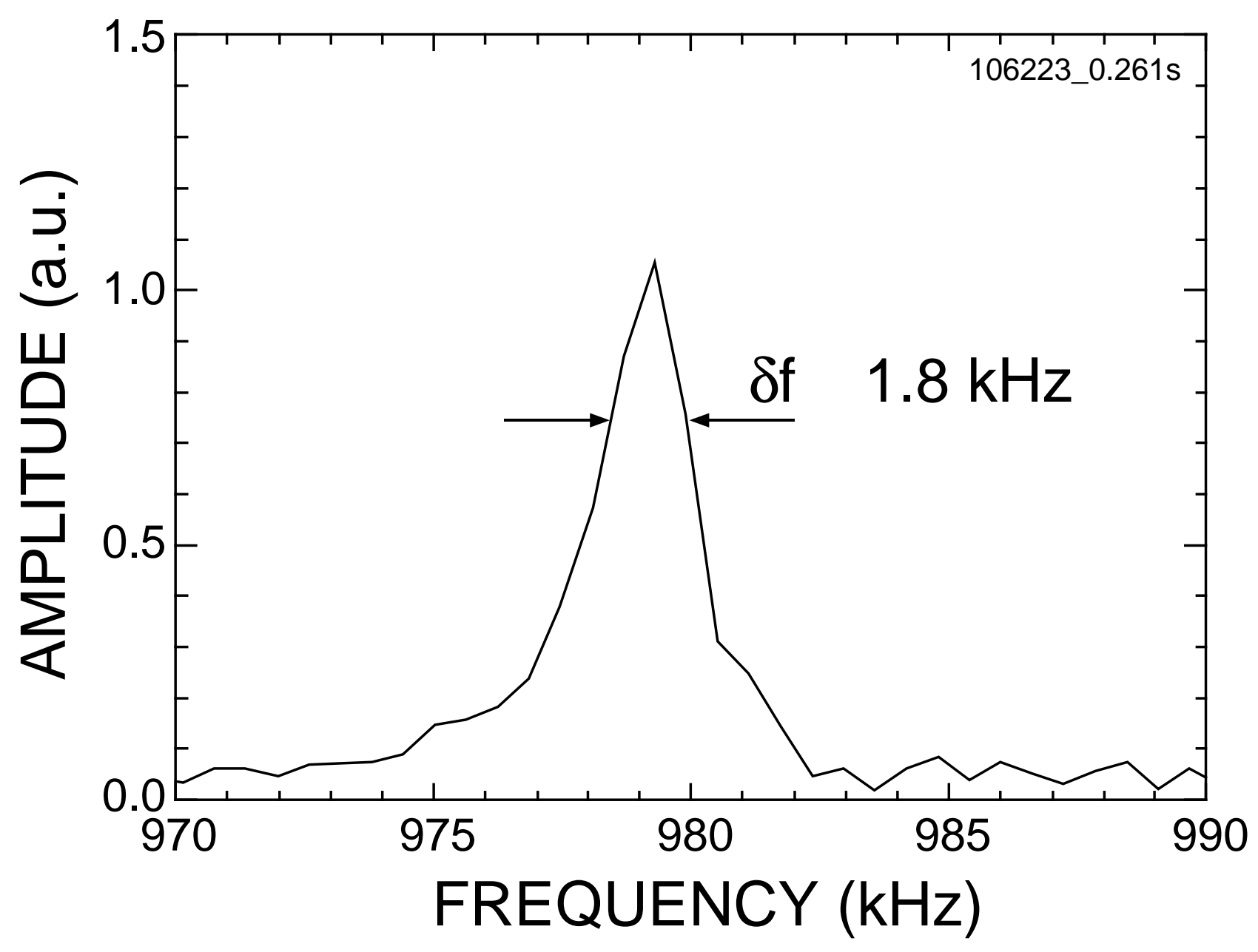


Figure 5

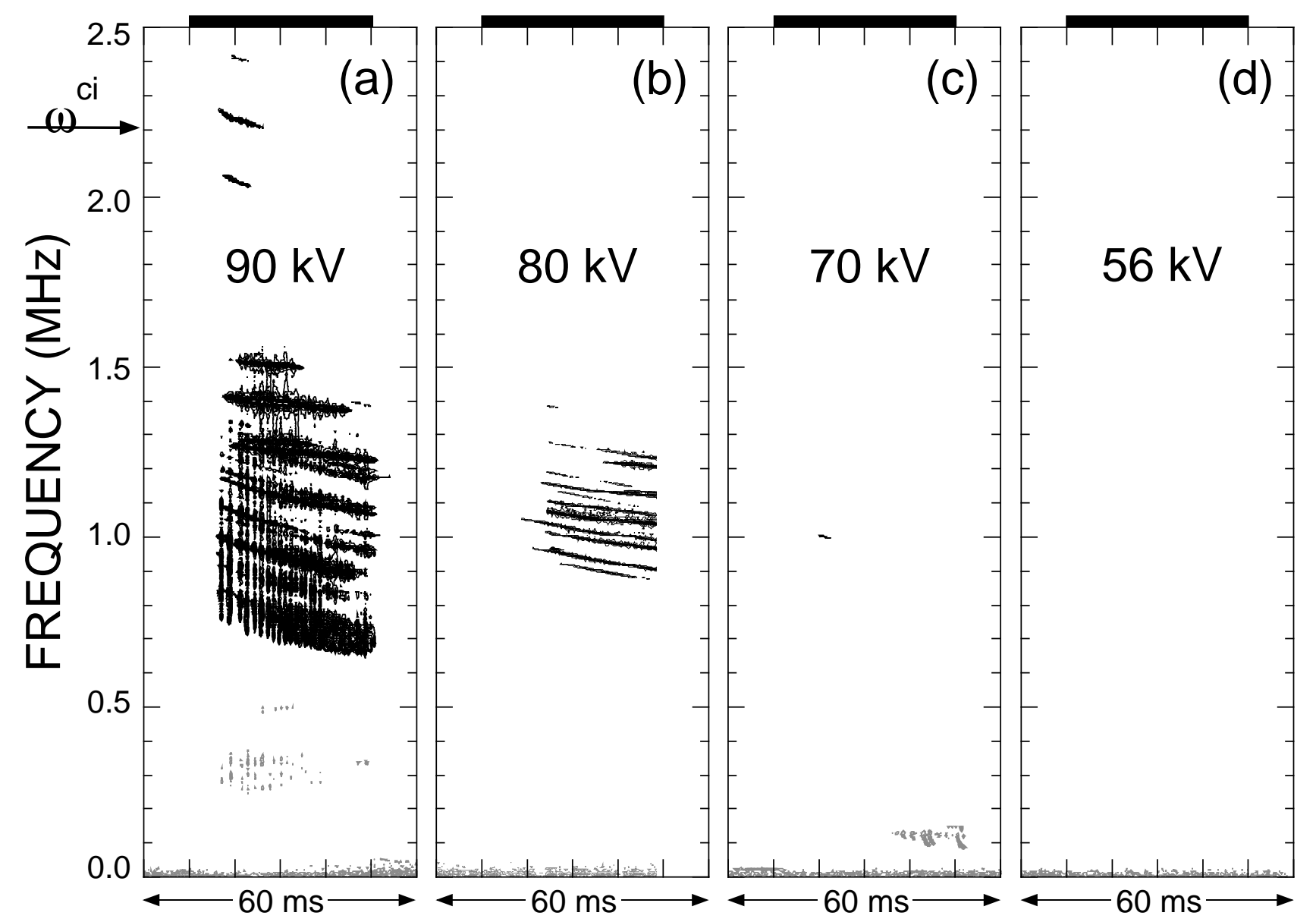


Figure 6

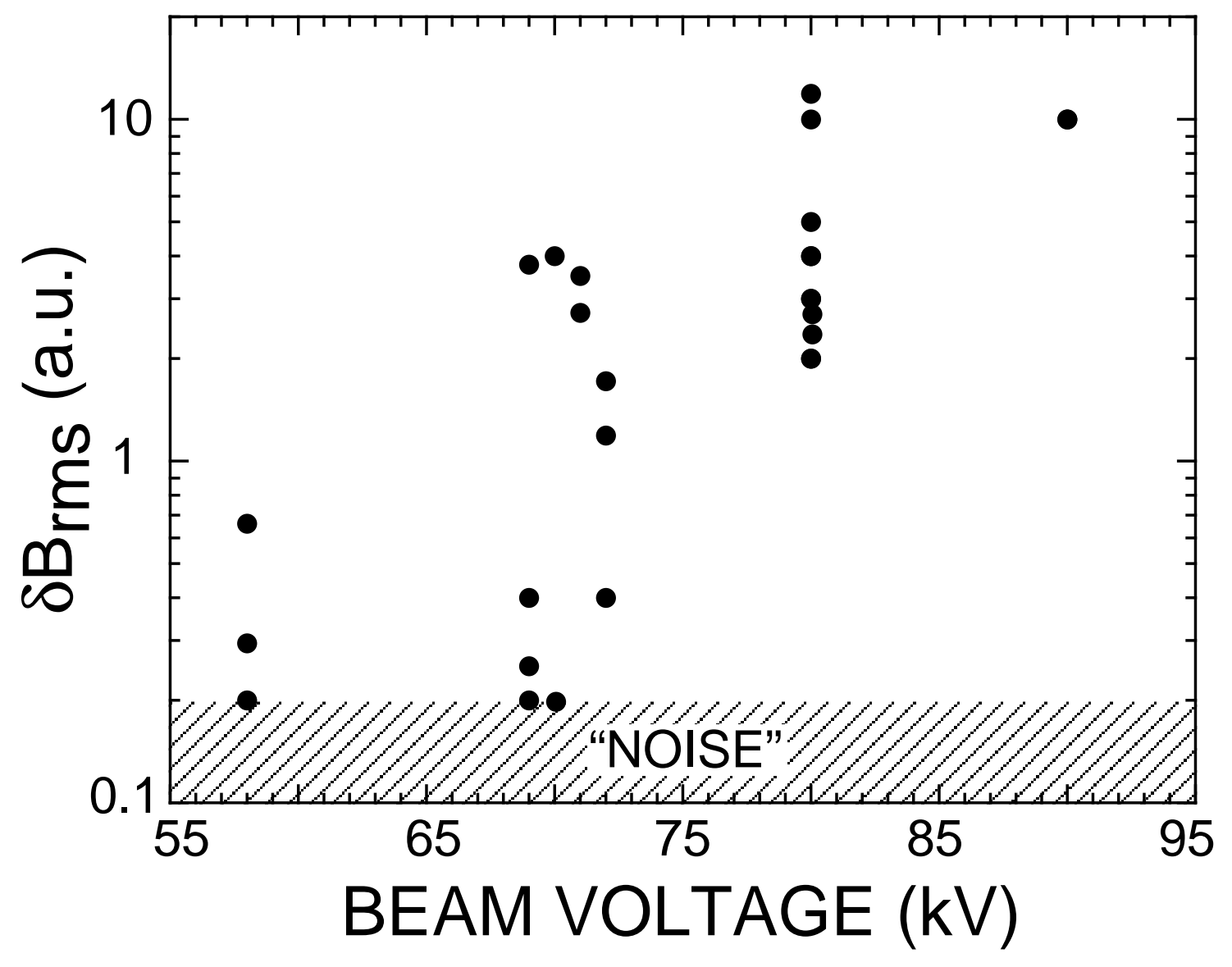


Figure 7

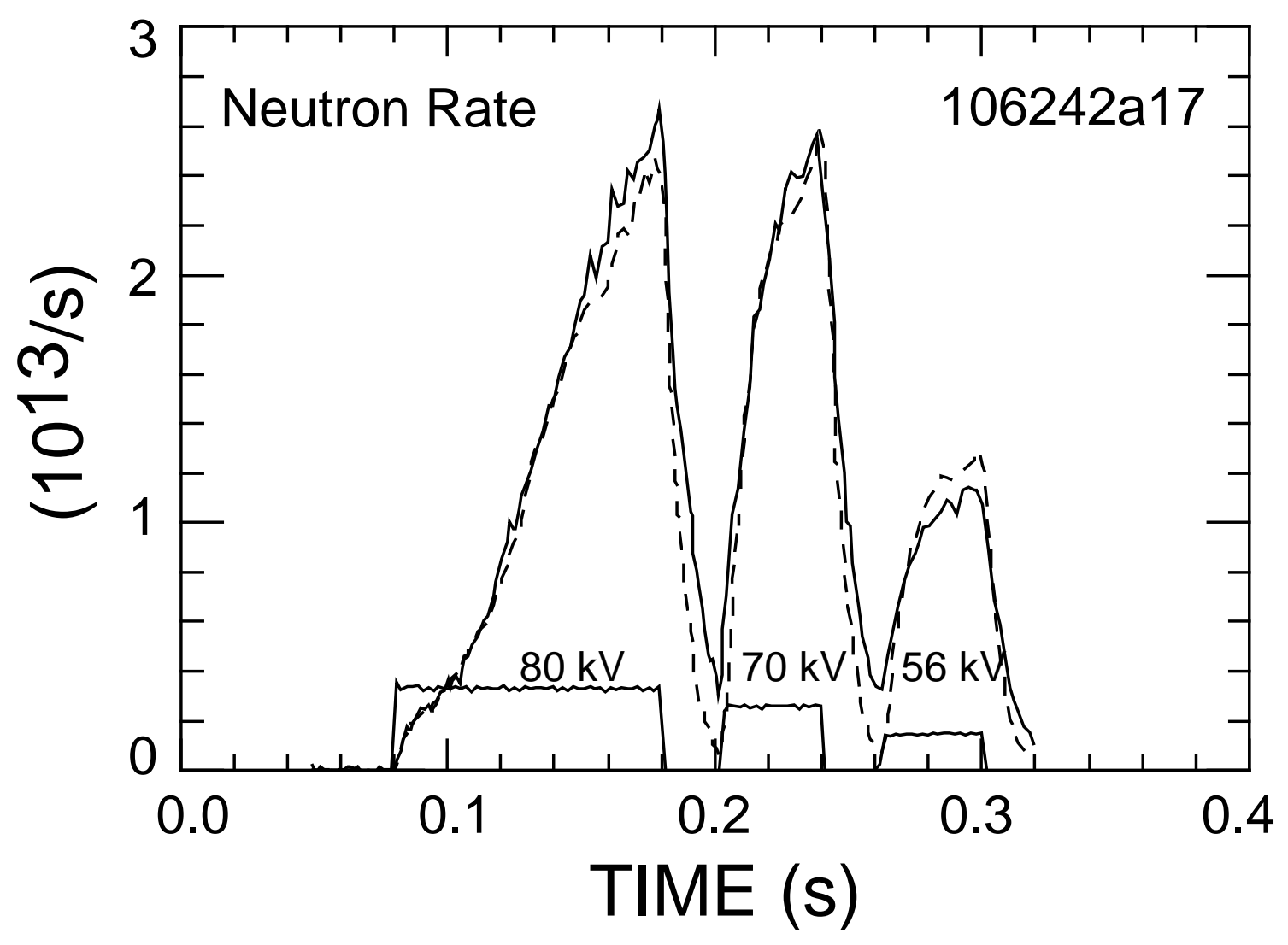


Figure 8

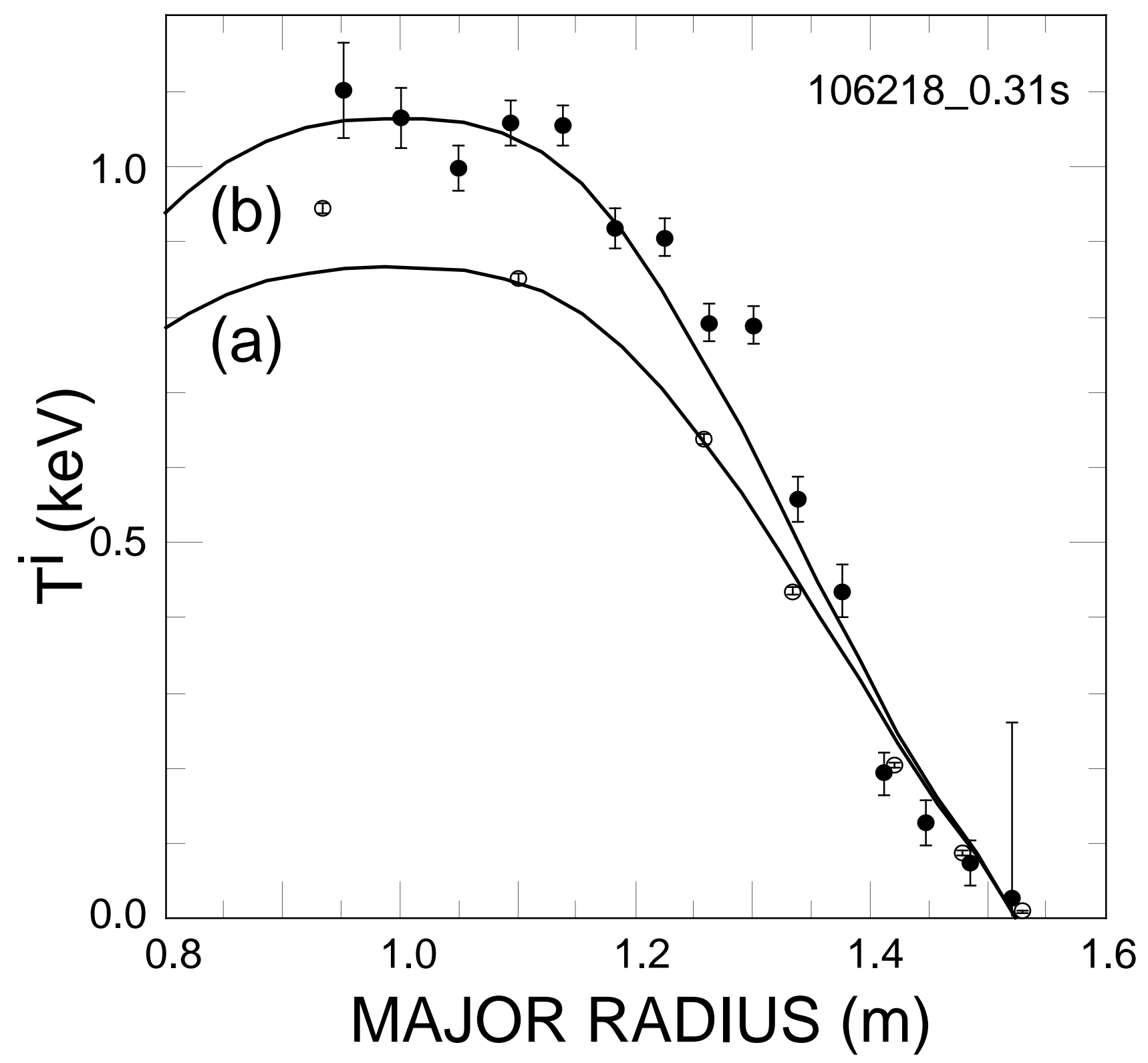


Figure 9

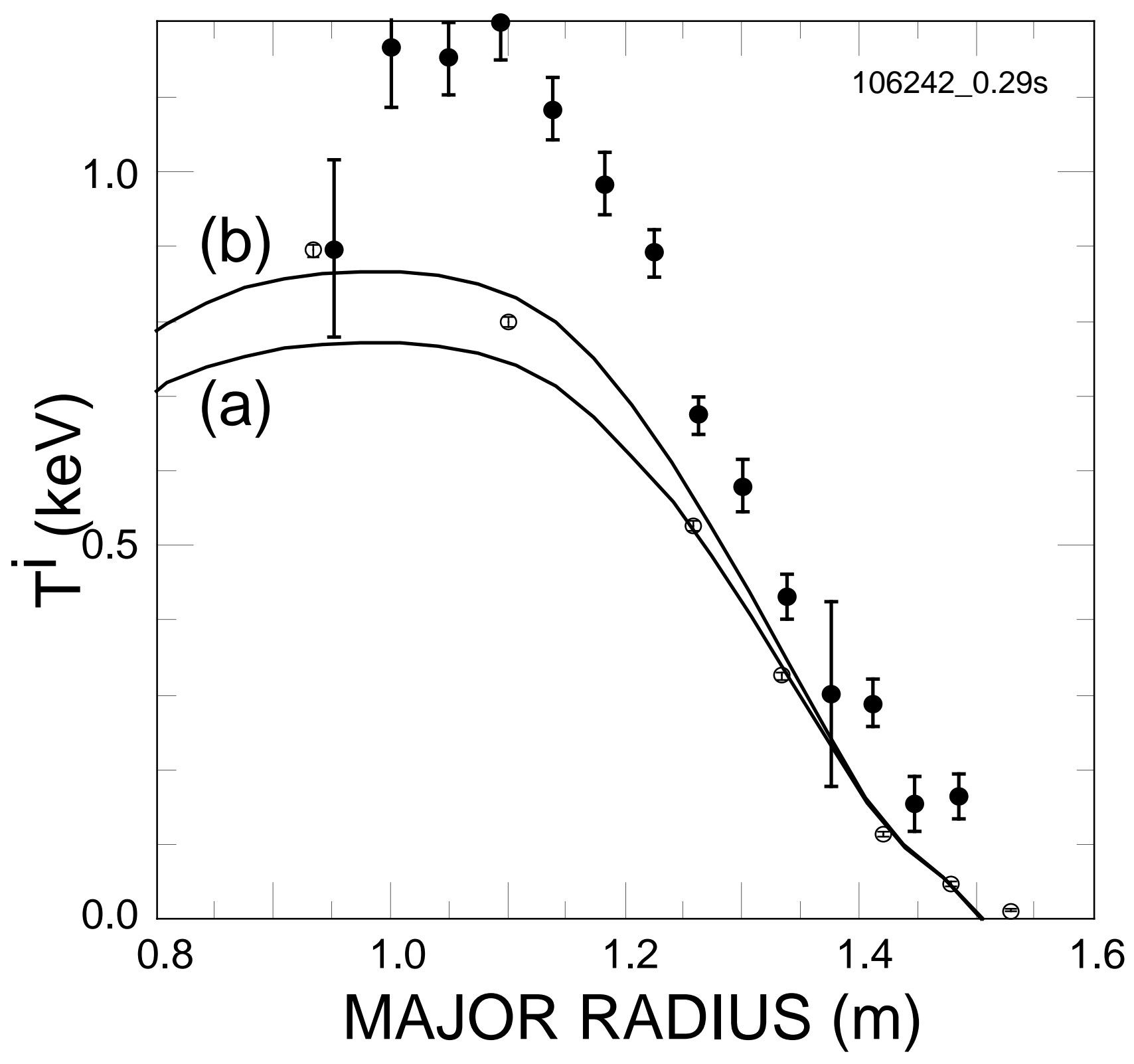




\section{External Distribution}

Plasma Research Laboratory, Australian National University, Australia

Professor I.R. J ones, Flinders University, Australia

Professor J oão Canalle, Instituto de Fisica DEQ/IF - UERJ , Brazil

Mr. Gerson O. Ludwig, Instituto Nacional de Pesquisas, Brazil

Dr. P.H. Sakanaka, Instituto Fisica, Brazil

The Librarian, Culham Laboratory, England

Library, R61, Rutherford Appleton Laboratory, England

Mrs. S.A. Hutchinson, JET Library, England

Professor M.N. Bussac, Ecole Polytechnique, France

Librarian, Max-Planck-Institut für Plasmaphysik, Germany

J olan Moldvai, Reports Library, MTA KFKI-ATKI, Hungary

Dr. P. Kaw, Institute for Plasma Research, India

Ms. P.J . Pathak, Librarian, Insitute for Plasma Research, India

Ms. Clelia De Palo, Associazione EURATOM-ENEA, I taly

Dr. G. Grosso, Instituto di Fisica del Plasma, Italy

Librarian, Naka Fusion Research Establishment, J AERI, J apan

Library, Plasma Physics Laboratory, Kyoto University, J apan

Research Information Center, National Institute for Fusion Science, J apan

Dr. O. Mitarai, Kyushu Tokai University, J apan

Library, Academia Sinica, Institute of Plasma Physics, People's Republic of China

Shih-Tung Tsai, Institute of Physics, Chinese Academy of Sciences, People's Republic of China

Dr. S. Mirnov, TRINITI, Troitsk, Russian Federation, Russia

Dr. V.S. Strelkov, Kurchatov Institute, Russian Federation, Russia

Professor Peter Lukac, Katedra Fyziky Plazmy MFF UK, Mlynska dolina F-2, Komenskeho Univerzita, SK-842 15 Bratislava, Slovakia

Dr. G.S. Lee, Korea Basic Science Institute, South Korea

Mr. Dennis Bruggink, Fusion Library, University of Wisconsin, USA

Institute for Plasma Research, University of Maryland, USA

Librarian, Fusion Energy Division, Oak Ridge National Laboratory, USA

Librarian, Institute of Fusion Studies, University of Texas, USA

Librarian, Magnetic Fusion Program, Lawrence Livermore National Laboratory, USA

Library, General Atomics, USA

Plasma Physics Group, Fusion Energy Research Program, University of California at San Diego, USA

Plasma Physics Library, Columbia University, USA

Alkesh Punjabi, Center for Fusion Research and Training, Hampton University, USA

Dr. W.M. Stacey, Fusion Research Center, Georgia Institute of Technology, USA

Dr. J ohn Willis, U.S. Department of Energy, Office of Fusion Energy Sciences, USA

Mr. Paul H. Wright, Indianapolis, Indiana, USA 
The Princeton Plasma Physics Laboratory is operated by Princeton University under contract with the U.S. Department of Energy.

\author{
Information Services \\ Princeton Plasma Physics Laboratory \\ P.O. Box 451 \\ Princeton, NJ 08543
}

Phone: 609-243-2750

Fax: 609-243-2751

e-mail: pppl_info@pppl.gov

Internet Address: http://www.pppl.gov 